\title{
The combined effects of salivas and occlusal indicators on occlusal contact forces
}

\author{
Christopher J. Beninati, Thomas R. Katona
}

\begin{abstract}
Background: Some occlusal detection products are designed for use on dry teeth, but this is not always achieved. Others are suited for dry and wet applications.

Objective: The objective of this study is to assess the combined effects, on occlusal contact forces, of two previously studied affecting variables - occlusal detection products and saliva.

Methods: We used a full arch dentiform with 3 occlusal detection products (an articulating film, an articulation paper and T-Scan) in combination with human (HS) and an artificial saliva. The maxillary arch assembly, weighing $\sim 54 \mathrm{~N}$ (the maximum bite force), was lowered onto (occlusion) and lifted off (disclusion) of the mandibular arch through 10 cycles by a mechanical testing machine. The forces and moments acting on the mandibular arch were continuously recorded by a load cell that supported it.
\end{abstract}

Results: The maximum values of $F_{\text {lateral }}$ (the in-occlusal plane component of the occlusal contact force) were analyzed by occlusion/disclusion separately using one-way ANOVA, with factor for group type to identify the significant effect of salivas on products, effect of products, effect of salivas with products, effect of human saliva. A difference in occlusion and/or in disclusion was considered different.

This is the author's manuscript of the article published in final edited form as:

Beninati, C. J., \& Katona, T. R. (2019). The combined effects of salivas and occlusal indicators on occlusal contact forces. Journal of Oral Rehabilitation, 0(ja). https://doi.org/10.1111/joor.12772 
Statistical differences $(p<0.0001)$ in $\mathrm{F}_{\text {lateral }}$ were found in: dry product vs. product $+\mathrm{HS}$, dry product vs. product + artificial saliva (with articulating film and T-Scan) and HS vs. product + HS (with articulation paper and T-Scan).

Conclusion: All products were affected by the salivas, except articulation paper by artificial saliva.

Keywords: dental occlusion, articulating film, articulation paper, T-Scan, bite force, saliva, friction

\section{Introduction}

Occlusion detection products are universal dental armamentaria in a wide range of clinical and laboratory situations. Some applications are relatively mundane (detecting a high restoration) while others are critical in establishing desired occlusal relationships and ameliorating pathologies such as TMD. Products range from a wide range of ordinary ink-based "carbon paper" type strips to the high-tech T-Scan computer-based system.

The traditional low-tech products are fraught with long-standing controversies about the products themselves, for example, the relationship between product thickness and the size/intensity of the ink marks that they leave on crowns, and about the clinical interpretation of those marks.(1, 2) For example, thicker products tend to produce larger markings.(3) Also disputed are some clinical procedures in which these products are indispensable. They include occlusal adjustments to treat $\mathrm{TMD}(4)$ and the minimizing of periodontium-damaging tipping forces by aligning occlusal forces with the long-axes of teeth.(5-7)

The presence of any of these products between teeth changes the natural crown-crown interface contact relationships to crown-product/product-crown interactions. Recent bench studies have demonstrated that this product-associated inherent change produces varying (generally significant) changes in the mechanical environments of teeth, namely in the magnitude and/or direction of the critical in-occlusal plane component $(5,7)$ of the occlusal force vector that acts on the teeth.

These previous studies were performed on pairs of denture,(8) stainless steel and/or ceramic crowns, while another(9) was with full dentiform arches. The studies examined several variables that directly affect occlusal contact forces, including 6 types of occlusal contact detection products, $(8,9)$ and human and 3 types of artificial salivas, $(10)$ and bite registration materials. Based

This article is protected by copyright. All rights reserved. 
on these studies, it can be generalized that all occlusal detection products characterize artefactual occlusions that they themselves create. These effects on occlusion are attributable to the geometric changes in the interfaces that are noted above, as well as the influence of friction(10-12) introduced by the various marking material inks and the salivas.

As no alternative exists, these products will continue to be used despite their critical flaws. Thus, one of our goals is to enable awareness on the part of clinicians about these major deficiencies. To that end, in this project, we examined the interactions of 2 previously reported variables, occlusal detection products and salivas, on their combined effects on occlusal forces. Some occlusal detection products (e.g., AccuFilm, tested in this study) are intended to be used with dry teeth,(13) but this is not always achieved clinically, while some products (e.g., Rudischhauser, also tested in this study) are advertised for dry or wet tooth applications.(14)

\section{Methods and Methods}

We used a full arch dentiform (Fig. 1; REF 600 210, 3M Unitek, Monrovia, CA, USA) with 3 types of occlusal detection products. They were AccuFilm I, an articulating film (AF; Stock No. S015, Single Sided Red pre-cut strip; Parkell Products, Edgewood, NY, USA), Rudischhauser Thick, an articulation paper (RT; Blue Improved Articulating Paper; Dental Articulating Paper, San Diego, CA, USA), and TScan, an electronic system (TS; Model 2001; Tekscan, South Boston, MA, USA) in combination with human saliva (HS; IRB approved bio bank \#1105005588) and an artificial saliva (Mouth-Kote, MK; Parnell Pharmaceuticals, San Rafael, CA, USA).

The dentiform was bolted into the testing apparatus in its well defined, maximum intercuspation position. The maxillary arch assembly, weighing $\sim 54 \mathrm{~N}$ (in effect, the maximum bite force), was guided by a pair of vertical precision slides (Mini-Guide, Double Carriage, Model \#SEBS 9BUU2-275, Nippon Bearing Co, Ojiya, Japan), Fig.1. A mechanical testing machine (MTS Bionix 858, MTS Corp., Minneapolis, MN, USA) was used to lower/raise the maxillary arch onto, and off of, the mandibular arch through 10 ramp cycles at $1.6 \mathrm{~mm} / \mathrm{sec}$. The latter was supported by a load cell (Delta SI-330-30, ATI Industrial Automation, Apex, NC, USA) that continuously recorded $(100 / \mathrm{sec})$ the force $(0-330 \mathrm{~N}$ $\pm 0.063 \mathrm{~N})$ and moment $(0-30 \mathrm{~N}-\mathrm{m} \pm 0.004 \mathrm{~N}-\mathrm{m})$ components that were acting on it, Fig. 2. The data was collected during occlusion $\left(\mathrm{F}_{\mathrm{z}}=0 \rightarrow 54 \mathrm{~N}\right)$ and disclusion $\left(\mathrm{F}_{\mathrm{z}}=\sim 54 \rightarrow \mathrm{N}\right)$.

The testing runs were performed as follows. Using the MTS, the weighted maxillary assembly was manually lowered onto the mandibular arch until a slight slack became apparent in the supporting chain, thereby indicating that the maximum occlusal force was being applied. This

This article is protected by copyright. All rights reserved. 
position of the MTS actuator was set as its lower limit. The programmed MTS ramp cycle was activated for 10 cycles (chomps) as the load cell measurements were recorded. This is D-1 in Table

1. Human saliva was then painted onto the occlusal surfaces, and 10 chomps were repeated, $\mathrm{H}-1$ in

Table 1. The teeth were cleaned (with 95\% ethanol on a cotton gauze) and dried, and the T-Scan product was rested on the lower arch and subjected to the 10 chomps, T-1. And, finally, human saliva was painted on the teeth and the T-Scan was positioned in place, HT-1.

The procedure was then repeated with AccuFilm instead of T-Scan and then with the Rudischhauser, $2^{\text {nd }}$ and $3^{\text {rd }}$ rows, respectively, in Table 1 . Then, the first 3 rows were redone to obtain the last 3 rows by substituting Mouth-Kote for human saliva as the wetting agent on the detection product. This change is reflected in the last column of Table 1.

From the load cell-measured $F_{x}$ and $F_{y}$ force components, the in-occlusal plane $F_{\text {lateral, }}$ and its direction, $\theta$ (Fig. 2), were calculated using the formulas:

$$
\mathrm{F}_{\text {lateral }}=\sqrt{\mathrm{F}_{\mathrm{x}}^{2}+\mathrm{F}_{\mathrm{y}}^{2}} \text { (the Pythagorean Theorem) and } \theta=\tan ^{-1}\left(\mathrm{~F}_{\mathrm{y}} / \mathrm{F}_{\mathrm{x}}\right) \text {. }
$$

\section{Statistical methods}

The maximum values of $\mathrm{F}_{\text {lateral }}$ were analyzed by occlusion and disclusion separately using one-way ANOVA, with factor for group type to identify the significant effect of salivas on products, effect of products, effect of salivas with products, and the effect of human saliva. All pair-wise comparisons from ANOVA analysis were made using Fisher's Protected Least Significant Differences to control the overall significance level at $5 \%$. A difference in occlusion and/or in disclusion was considered different.

Results

For the visualization of results, several examples are displayed in Fig. $\mathbf{3}$ in the form of vector arrows. All results are presented in Fig. 4.

Statistical differences $(p<0.0001)$ in the maximum value of $F_{\text {lateral }}$ were found in:

- Dry product vs. Product + HS (for AF, RT and TS)

This article is protected by copyright. All rights reserved. 
- Dry product vs. Product + MK (for AF and TS)

- HS vs. Product + HS (for RT and TS)

- MK vs. Product + MK (for AF, RT and TS)

That is, all of the products were affected by the salivas, except RT by MK.

\section{Discussion}

The physics of occlusal contacts is a basic, but complex, mechanical engineering subject that involves multiple simultaneous sliding contacts between inclined (cusp) planes, with the confounding effects of friction.(12) The individual occlusal contact forces are vector quantities because, by definition, vectors are characterized by a magnitude and a direction. Furthermore, the characterization of a force vector also requires its point-of-application (or its line-of-action (LOA)). Thus, 2 force vectors are equal only if their magnitudes, directions and LOAs are equal.

When a detection product is placed between contacting teeth, the interface relationships change from a crown-crown interaction to a crown-product/product-crown interaction. It therefore follows that the individual contact force vectors also change (in direction, magnitude and/or LOA) because of the geometric alterations. In addition, the 2 contacting materials are different, thereby altering the friction forces between the sliding surfaces. Friction is also affected by the presence of a saliva.

Technology to directly measure individual occlusal contact forces does not exist. But, by supporting the mandibular tooth with a load cell, the design of this experimental apparatus allows for the measurement of the combined effects of changes in all of the contact forces. That is, a change in a load cell reading can be caused only by a change in the magnitude and/or direction and/or LOA of at least one of the cusp incline contact forces. Thus, if the load cell readings are different, it can be concluded that the contact forces are different.

Studies (8-10) using this approach have been performed on single pairs of denture teeth (with various cusp angulations), stainless steel and ceramic crowns, and full-arch dentiforms. These studies examined the effects of six occlusal detection materials and (human and various artificial) salivas. In general, the results confirmed the intuitive notion that, essentially, the introduction of occlusal detection products between teeth produces an artefactual occlusion. We attribute this to the geometric effects of changing the natural crown-crown occlusal contacts to a crown-product-

This article is protected by copyright. All rights reserved. 
crown interface. And, similar to the previously demonstrated effects of the salivas, the detection products also influence the friction between the sliding surfaces. In this study we examined the combined effects of these previously investigated variables so as to assess if there may be other issues with the clinical use of these products.

The statistical analyses were based on the maximum magnitudes of the $F_{\text {lateral }}$ force component, Fig. 2 , as it is considered destructive to the periodontium. $(5,7)$ We looked at the quantitative changes in the occlusion, as reflected in $F_{\text {lateral, }}$ that is caused by the combined presence of a detection product and a saliva. We were not at all interested in the clinical assessment of the occlusion, i.e., the ink markings and their interpretations, nor the T-Scan recorded digital data. Our focus is on the occlusion itself.

There are 2 controls in the study design. They are the $1^{\text {st }}$ (Human saliva) and $2^{\text {nd }}$ (Dry) columns in Fig. 4 and Table 1. They are intended, respectively, for comparisons with the natural situation and for some product-use instructions for dry teeth. Furthermore, each set (row in Fig. 4 and Table 1) has its own controls. (This was to counter the possible cumulative effects of minute distortions in the apparatus.)

A cursory examination of the partial data displayed in Fig. 3 reveals the inherent problem with these products. All HS-associated $\mathrm{F}_{\text {lateral }}$ vectors $(\mathrm{H}-3)$ act in the posterior-left direction. The dry RT (R-3) forces deviate more towards the left, while the TS-HS (HT-1) combination $\mathrm{F}_{\text {lateral }}$ vectors act anteriorly. Also note the concomitant $\mathrm{F}_{\text {lateral }}$ magnitudes, with the HT-1 group being about half that of the H-3 group. Thus, the markings left by R-3 and the electronic data recorded in HT- 1 are produced by artefactual occlusions that do not resemble the "patient's" natural occlusion, H-3. A more careful observation of Fig. 3 demonstrates that $\mathrm{H}-3$ remains relatively unchanged from the $1^{\text {st }}$ to the $10^{\text {th }}$ chomp. In contrast, R-3 exhibits changes in direction and magnitude, more so than HT-1.

In concordance with previous results,(9) $F_{\text {lateral }}$ is not consistently smaller/larger during occlusion than disclusion, solid vs. dashed lines in Figs. $\mathbf{4 a}$ and $\mathbf{c}$, although when the occlusion/disclusion magnitude difference is large, it is generally the case, somewhat counterintuitively, that disclusion > occlusion. More relevant to our purposes, however, is another counterintuitive observation that the maximum value of $F_{\text {lateral, }}$, the focus of the study, does not necessarily occur with the maximum value of the bite force, $F_{z}$. This can be seen on the right sides of the panels in Figs. $4 a$ and $c$.

The instructions for the use of the detection products raise some issues. It is recommended that AccuFilm be used dry.(13) Our analysis indicates that there is a difference in the dry vs. wet $F_{\text {lateral }}$ (A2 vs. HA-2 in Fig. 4a), but it is likely that the recommendation is based on the legibility of the

This article is protected by copyright. All rights reserved. 
markings. Furthermore, for those reasons, the instructions suggest coating the teeth with Vaseline. Although not based on any tests, it is likely that petroleum jelly has a substantial impact on friction, and therefore, on the occlusion. Thus, the marks may be more distinct, but they are unlikely to be of the same occlusion. (Note that we do not place emphasis on MT-4, MA-5 and MR-6 results because they are improbable clinical combinations. That is, it would be unusual for a patient to use MouthKote during a dental exam.)

According to the Rudischhauser instructions,(14) the product can be used dry or wet, likely based on marking readability considerations. However, our results indicate that the dry vs. wet $F_{\text {lateral }}(R-3$ vs. HR-3 in Fig. 4a) are different. So, the markings may be adequate, dry or wet, but they are not produced by the same occlusion. Also note the complex results involving the Rudischhauser, Fig. 4. We believe that the main explanation is that the sliding contacts must "plough" through the inked coating on the surface of the ribbon, and with each chomp, there is less of the coating remaining along the slide path. Other contributing factors may be an ever decreasing thickness of the ribbon, and friction changes associated with the surface changes occurring on the ribbon surface.

\section{Conclusions}

All products were affected by human saliva. AccuFilm I is recommended for use in a dry environment. Our results show that it will create a different occlusion if exposed to saliva. Rudischhauser Thick can be used dry or wet, but the 2 conditions, as with AccuFilm and T-Scan, produce different occlusions. Essentially, therefore, the artefactual occlusions that are inherent to these products to begin with, are simply modified to different artefactual occlusions.

\section{Disclosures}

The authors have no conflicts of interest, ethics approval was not required, and only internal support was utilized. We thank Ms. Qing Tang and Mr. George Eckert for their assistance.

This article is protected by copyright. All rights reserved. 


\section{References}

1. Carey JP, Craig M, Kerstein RB, Radke J. Determining a relationship between applied occlusal load and articulating paper mark area. Open Dent J. 2007;1:1-7.

2. Saad MN, Weiner G, Ehrenberg D, Weiner S. Effects of load and indicator type upon occlusal contact markings. J Biomed Mater Res B Appl Biomater. 2008;85:18-22.

3. Schelb E, Kaiser DA, BrukI CE. Thickness and marking characteristics of occlusal registration strips. J Prosthet Dent. 1985;54:122-126.

4. Katona TR. Engineering analyses of the link between occlusion and temporomandibular joint disorders. International Journal of Stomatology \& Occlusion Medicine. 2013;6:16-21.

5. Dawson PE. Functional occlusion: from TMJ to smile design. St. Louis: Mosby; 2007.

6. Katona TR. An engineering analysis of dental occlusion principles. Am J Orthod Dentofacial Orthop. 2009;135:696.e691-698; discussion 696-697.

7. Okeson JP. Management of temporomandibular disorders and occlusion. Saint Louis: Mosby; 2008.

8. Helms RB, Katona TR, Eckert GJ. Do occlusal contact detection products alter the occlusion? J Oral Rehabil. 2012;39:357-363.

9. Mitchem JA, Katona TR, Moser EAS. Does the presence of an occlusal indicator product affect the contact forces between full dentitions? J Oral Rehabil. 2017;44:791-799.

10. McCrea ES, Katona TR, Eckert GJ. The effects of salivas on occlusal forces. J Oral Rehabil. 2015;42:348-354.

11. Katona TR. A mathematical analysis of the role of friction in occlusal trauma. J Prosthet Dent. 2001;86:636-643.

12. Katona TR, Eckert GJ. The mechanics of dental occlusion and disclusion. Clin Biomech (Bristol, Avon). 2017;50:84-91.

13. Parkell. Instructions for Use - AccuFilm. https://cdn2.hubspot.net/hubfs/498577/IFUs/AccuFilm_ifu.pdf. accessed.

14. Patterson. G. E. Rudischhauser Articulating Paper. https://www.pattersondental.com/Supplies/ProductFamilyDetails/PIF_51446. accessed.

This article is protected by copyright. All rights reserved. 
Table 1. Experimental groups.

\begin{tabular}{ccccccc}
\hline & Dry teeth & Human saliva & \multicolumn{2}{c}{ Dry products } & \multicolumn{2}{c}{ Wet products } \\
\hline Human & D-1 & H-1 & TS & T-1 & TS + HS & HT-1 \\
saliva & D-2 & H-2 & AF & A-2 & AF + HS & HA-2 \\
(HS) & D-3 & H-3 & RT & R-3 & RT + HS & HR-3 \\
\hline Mouth- & D-4 & H-4 & TS & T-4 & TS + MK & MT-4 \\
Kote & D-5 & H-5 & AF & A-5 & AF + MK & MA-5 \\
(MK) & D-6 & H-6 & RT & R-6 & RT + MK & MR-6 \\
\hline
\end{tabular}

This article is protected by copyright. All rights reserved. 


\section{Figure Legends}

Fig. 1. Testing apparatus.

Fig. 2. The $x-y-z$ coordinate system and the associated force and moment components acting on the arch and measured by the load cell.

Fig. 3. Graphs of the load cell-measured $F_{y}$ vs. $F_{x}$ produce vector representations of $F_{\text {lateral }}$ acting on the mandibular arch, which is depicted in the $1^{\text {st }}$ panel. The solid arrows represent occlusion as $F_{z}$ (the occlusal force) increases from $5 \rightarrow 20 \rightarrow 35 \rightarrow 50(N)$. Disclusion, $\mathrm{F}_{2}=50 \rightarrow 35 \rightarrow 20 \rightarrow 5(\mathrm{~N})$ is symbolized by the dashed arrows. (The $F_{z}$ values are shown in the $1^{\text {st }}$ panel.)

Fig. 4. All results for (a) $F_{\text {lateral }}$ for the human saliva group and (b) the corresponding $\theta$. Similarly (c and d) for the Mouth-Kote group. Solid lines are occlusion, dashed lines are disclusion. Blow-up in the $1^{\text {st }}$ panel of (a) demonstrates that, in some instances, the 10 chomps overlap. By contrast, the 1 $\rightarrow 10$ labelled arrows in the R-3 panel (Fig. 4a) highlight results in which the chomps (from the $1^{\text {st }}$ to the $10^{\text {th }}$ ) produce progressively different results.

This article is protected by copyright. All rights reserved. 


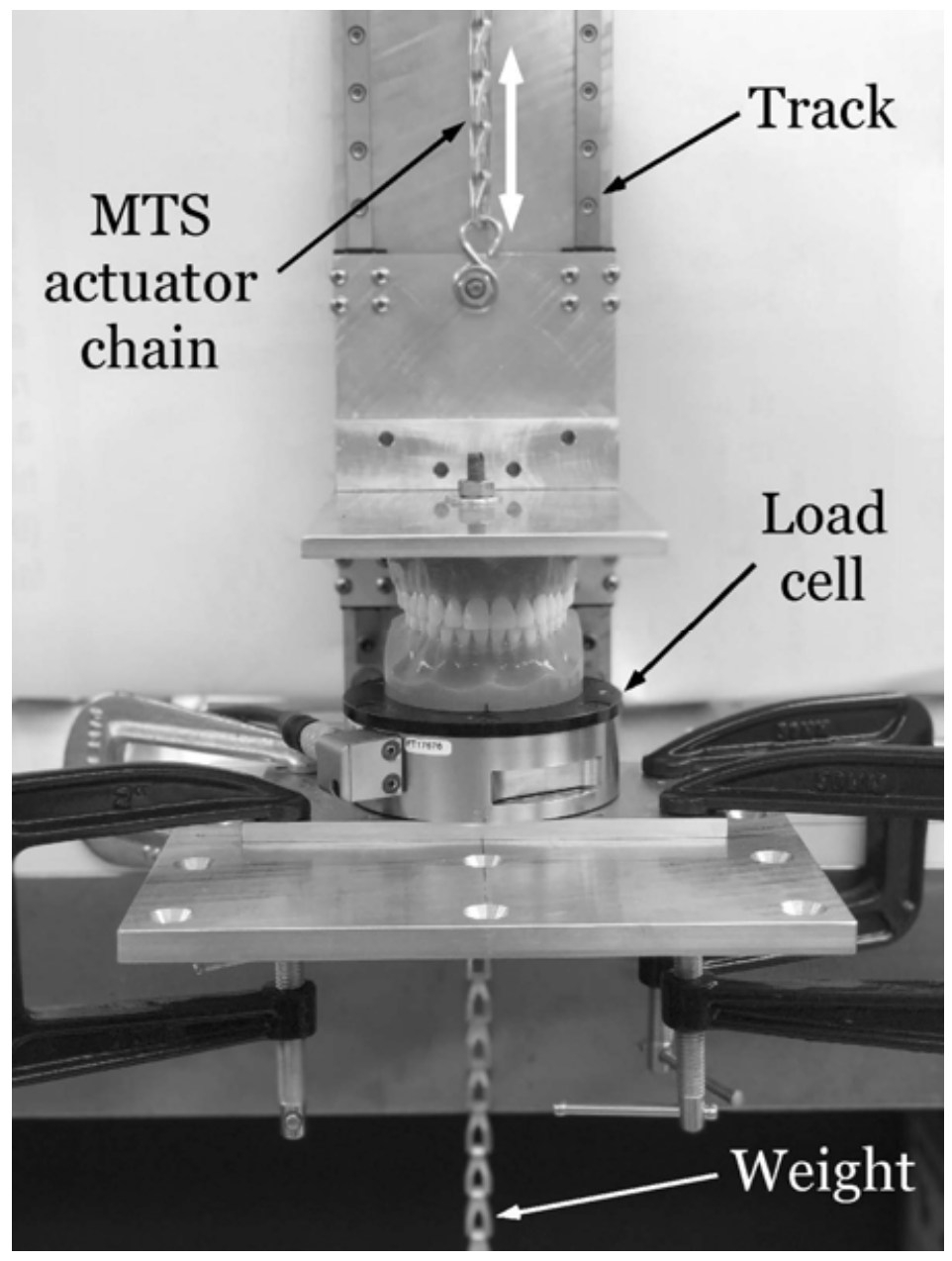

This article is protected by copyright. All rights reserved. 

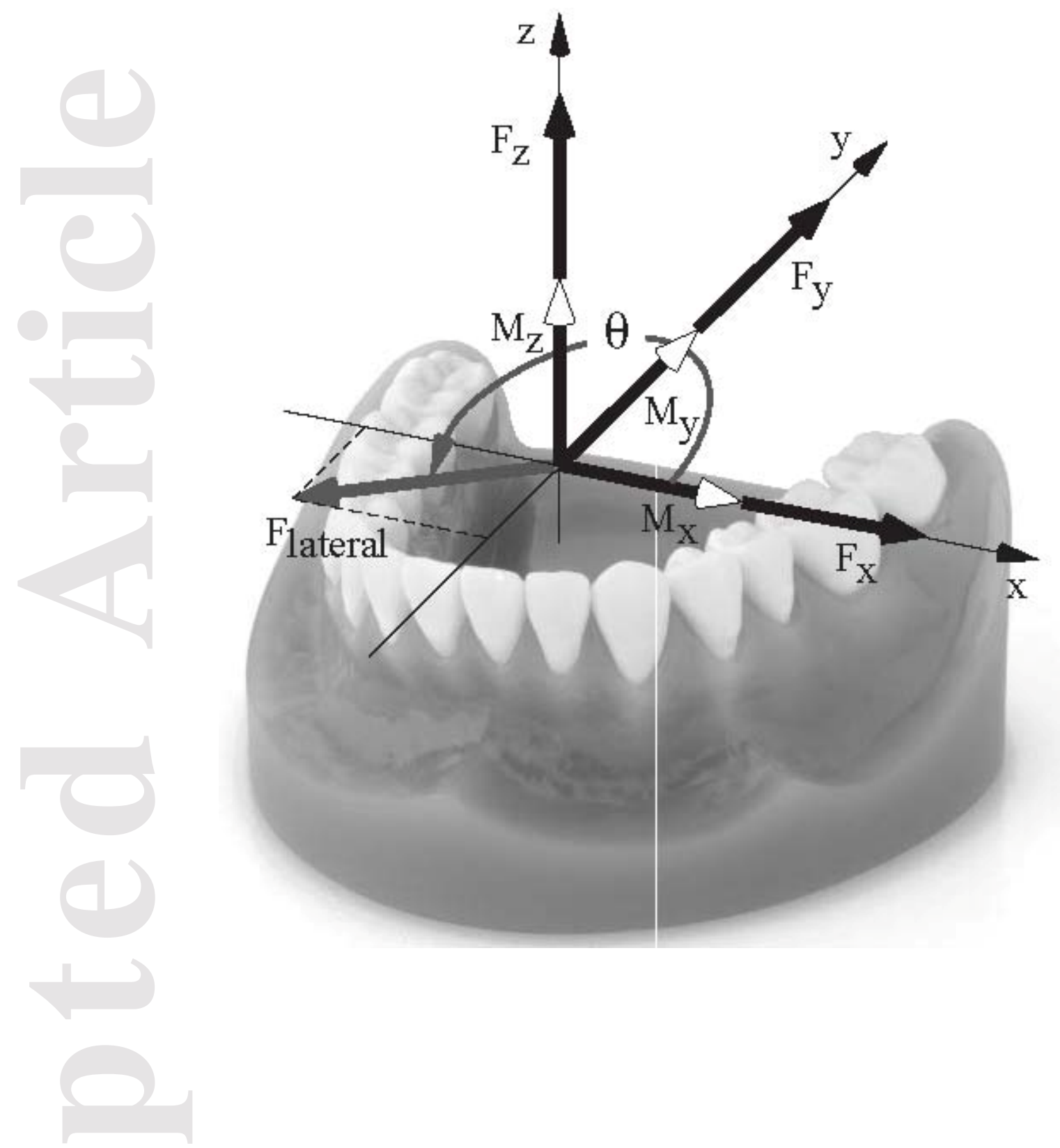

This article is protected by copyright. All rights reserved. 


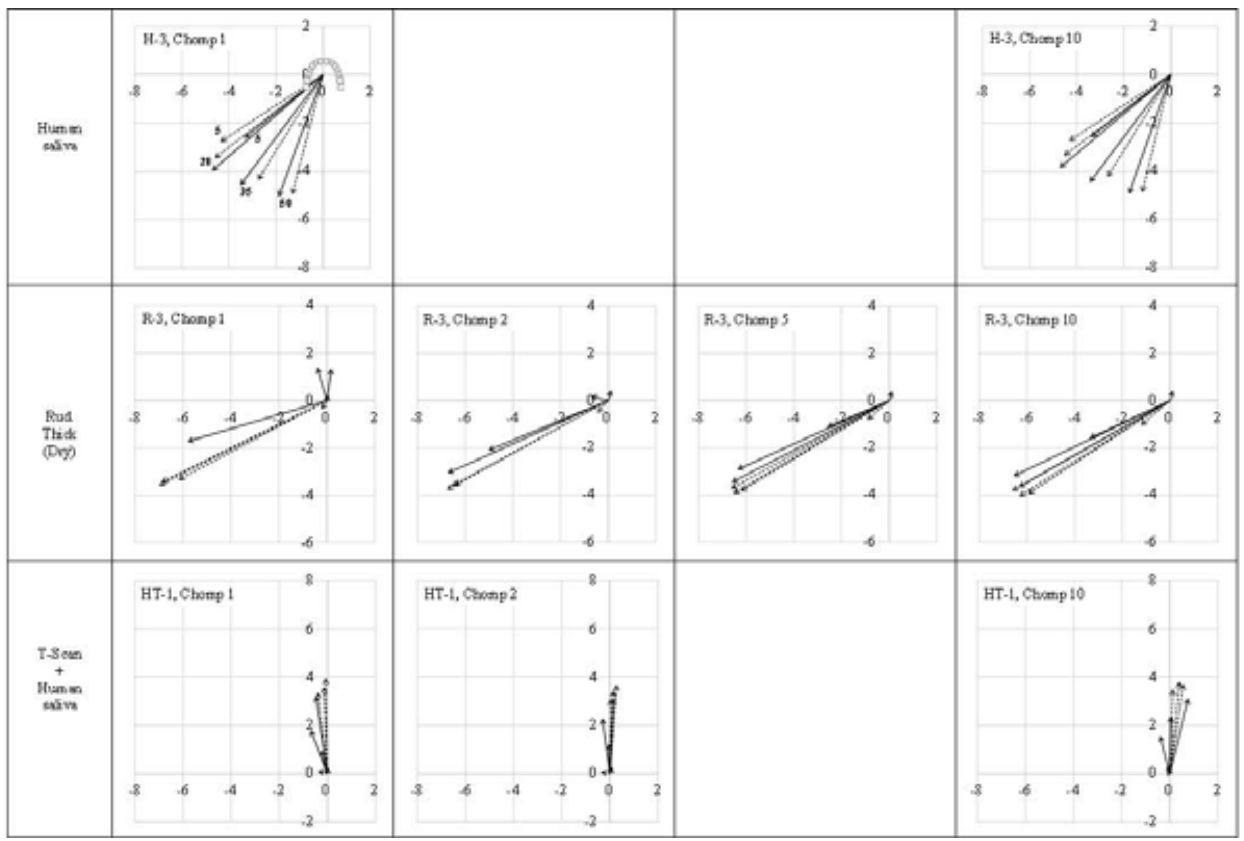

This article is protected by copyright. All rights reserved. 


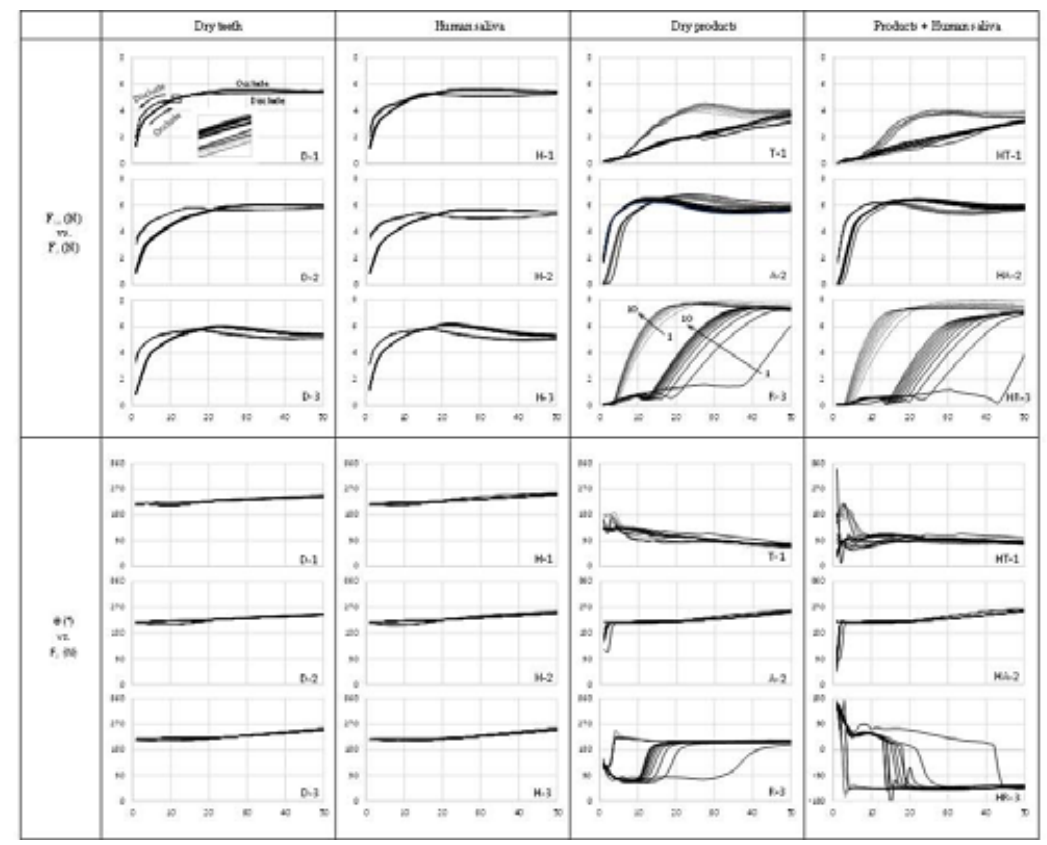

This article is protected by copyright. All rights reserved. 


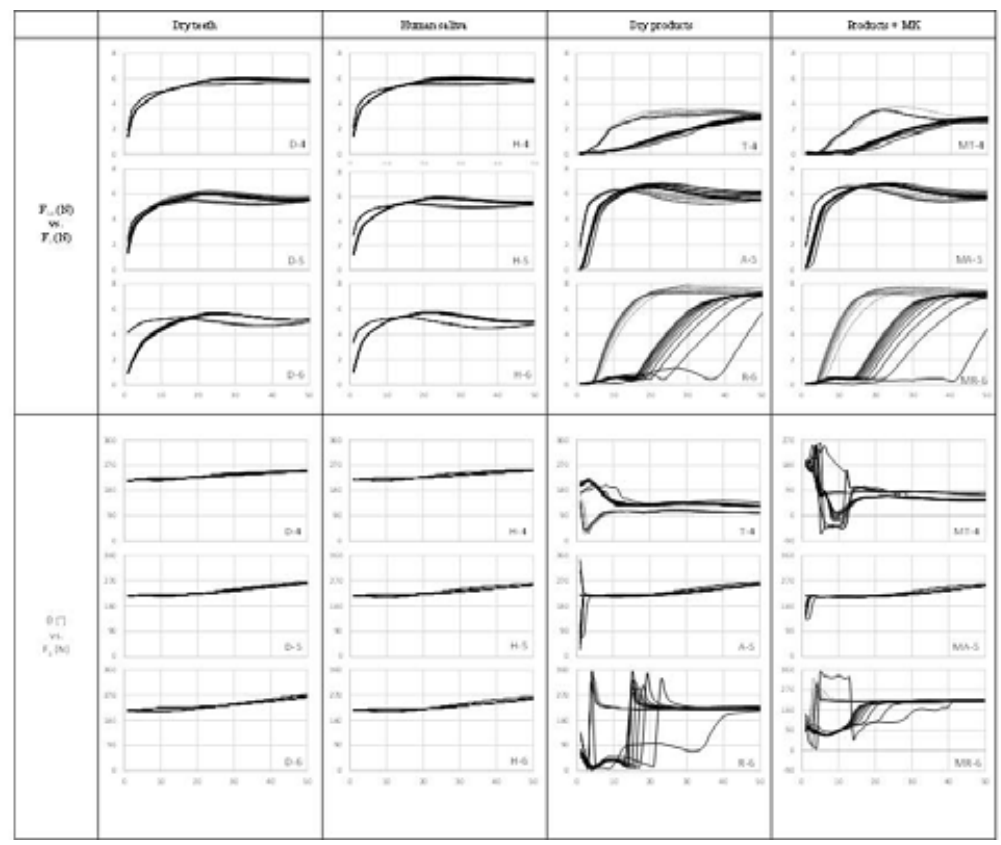

This article is protected by copyright. All rights reserved. 